\title{
As várias faces do fundamentalismo protestante no Brasil: por uma discussão terminológica e conceitual
}

\author{
Multiple faces of fundamentalist protestantism in Brazil: \\ a conceptual and terminological discussion
}

Breno Martins Campos*

\begin{abstract}
Resumo
Como resultado de pesquisa bibliográfica de fontes não necessariamente unânimes entre si, este artigo contribui para a compreensão do campo evangélico no Brasil por comparação com a realidade estadunidense do passado e do presente, e pela discussão das relações do fundamentalismo com o neofundamentalismo, o pentecostalismo e o neopentecostalismo (ou pós-pentecostalismo). O objetivo geral perseguido ao longo das seções é demonstrar que, hoje, fundamentalismo é um termo que nomeia vários fenômenos; e que, portanto, é mais adequado observar (para entender) o que fazem os fundamentalistas do que esboçar quaisquer definições conceituais. Por não ser uma igreja ou denominação instituída, o fundamentalismo no Brasil vai da presença no protestantismo histórico à circulação dentre os neopentecostais; do pré-milenarismo dispensacionalista do pentecostalismo tradicional ao pós-milenarismo adaptado dos pós-pentecostais. Em contrapartida, ao longo do século XX e até hoje, num ponto todas as faces do fundamentalismo concordaram e ainda tendem a concordar: há uma única verdade (retirada de muitos modos da mesma Bíblia) e, como consequência, o divergente precisa mudar, caso contrário, torna-se intolerável - funcionamento que revela o fanatismo dos fundamentalistas. Mais recentemente, a política foi o caminho adotado para a entrada dos fiéis no espaço público e para a tentativa de conversão, ainda que à força, da sociedade à moralidade dos fundamentalistas.
\end{abstract}

Palavras-chave

Protestantismo. Fundamentalismo. Pentecostalismo. EUA. Brasil.

Abstract

[Texto recebido em dezembro de 2016 e aceito em junho de 2017, com base na avaliação cega por pares realizada por pareceristas ad hoc]

* Doutor em Ciências Sociais. Professor do corpo docente permanente do Programa de Pós-Graduação em Ciências da Religião da PUC-Campinas. E-mail: brenomartinscampos@gmail.com

* Mestre em Ciências da Religião. Programa de Pós-Graduação em Ciências da Religião da PUC-Campinas. E-mail: saulo.isilva@hotmail.com 


\begin{abstract}
As a result of not necessarily unanimous bibliographical sources research, this article contributes to a comprehension of the evangelical field in Brazil by comparing it with the past and present North American reality. It also discusses the relationships between Fundamentalism and NeoFundamentalism, Pentecostalism and Neo-Pentecostalism. The overall objective is to demonstrate that, nowadays, Fundamentalism is a term that names several phenomena; and therefore is more adequate to observe (in order to understand) the fundamentalism practices than to propose some conceptual definitions. As it is not an institutionalized church or denomination, Fundamentalism in Brazil encompasses from the historical Protestantism to the Neo-Pentecostalism; it goes from the dispensational Pre-Millennialism of the traditional Pentecostalism to the postMillennialism adapted by the Neo-Pentecostals. On the other side, throughout the 20th Century up to our days, at least in one point all faces of fundamentalism have agreed and still tend to agree: there is only one truth (extract by several ways from the same Bible). As a consequence, the divergent needs to change. If the other does not change, he becomes intolerable. This aspect reveals a typical fanatical behavior of fundamentalists. More recently, politics has been the way adopted by the entrance of fundamentalist faithfuls in the public sphere and for an attempt of conversion, even if enforced, of the society to the fundamentalist morality.
\end{abstract}

\title{
Keywords
}

Protestantism. Fundamentalism. Pentecostalism. USA. Brazil.

\section{Introdução}

Como um passo a mais na direção da compreensão do campo religioso protestante, com ênfase no caso brasileiro, o objetivo geral deste artigo é o de discutir a relação entre algumas palavras - fundamentalismo, neofundamentalismo, pentecostalismo, neopentecostalismo - e os fenômenos religiosos que elas pretendem nomear. Para tanto, dois limites ou desafios foram incorporados à pesquisa: o primeiro é o reconhecimento de que os nomes elencados são utilizados pelo senso comum e também por sujeitos localizados no espectro da sociologia espontânea dentro do campo científico e do jornalístico, portanto, nem sempre da mesma maneira nem com os mesmos significados; o segundo é o consentimento de que o caminho acadêmico do rigor semântico aventado aqui é um dentre outros possíveis, ou seja, os resultados alcançados são coerentes com os referenciais teóricos e bibliográficos adotados, mas não têm a pretensão de unanimidade.

Antes de quaisquer definições, destacam-se três das consequências teológicas e sociais do fundamentalismo religioso que atingem mentalidades e ações de indivíduos e coletividades: a intolerância, o fanatismo e, na base de tudo, a absolutização da verdade. Dada a complexidade do caso, tenciona-se demonstrar que a compreensão do que fazem os fundamentalistas se encontra mais acessível à observação do que a significação de 
conceitos. O modelo prototípico adotado como objeto de investigação, com o qual os outros podem ser comparados, é o fundamentalismo protestante, cuja emergência ocorreu nos EUA, no final do século XIX e, mais objetivamente, no início do século passado.

Os pais do primeiro fundamentalismo acreditavam e defendiam que somente a rígida moral cristã, conforme sua própria definição, poderia trazer de volta o passado ao cenário social (idealizado como uma espécie de era dourada perdida pela humanidade). Militantes fundamentalistas traçavam princípios a guiar seus ideais e ações, principalmente a doutrina da inerrância bíblica - ou infalibilidade, para os que preferem relativizar a questão -, da qual decorre toda sua dogmática; eles questionavam na modernidade as explicações científicas contrárias aos princípios bíblicos e se opunham, principalmente, ao darwinismo e seu ensino nas escolas públicas estadunidenses.

A sustentação da intolerância pelo fundamentalismo protestante é corolário da aceitação tácita de que a Bíblia é um referencial que exige leitura sem crítica ou questionamento; e que estabelece a adesão a rígidos saberes doutrinários. Como resultado, líderes religiosos fundamentalistas oferecem dupla proteção aos fiéis de sua igreja ou denominação: a espiritual ou subjetiva, contra as dúvidas de dentro e de fora do campo religioso (provenientes da razão crítica e do diálogo ou mero encontro com o diferente), e a institucional, contra a concorrência de outros fundamentalismos e também contra a crítica de dissidentes ou renegados.

Em face de certas condições sociais vigentes durante todo o século XX - e que ainda perduram -, há aqueles que cultivam a esperança do surgimento de uma saída imediata que faça diminuir o sofrimento. Abrem-se ao fanatismo, para o qual a leitura literalista da Bíblia serve de alicerce em meio às ameaças do tempo presente, notadamente a perda ou enfraquecimento de valores tradicionais. Trata-se de um modelo em que o estudo do texto sagrado em contexto religioso se dá mais por memorização de conteúdo do que propriamente pela necessária mediação hermenêutica; o cânon passa a ser um depósito de certezas num mundo de inseguranças. ${ }^{1}$ Essa proposta de leitura fundamentalista da Bíblia é a de captar evidências (exigidas pelas doutrinas) e que supostamente se sustentam por si mesmas.

Para entrar no terreno das definições, ${ }^{2}$ considera-se o fundamentalismo protestante uma forma de religiosidade moral militante própria do século $\mathrm{XX}$, como consequência de eventos anteriores ainda no século XIX. O fundamentalismo originário possuía características tradicionais de interpretação do passado, que visavam a se contrapor a valores da sociedade moderna; mais tarde, assumiu também como um de seus

1 WITHERUP, Ronald D. Fundamentalismo bíblico: o que todo católico deveria saber. São Paulo: Ave-Maria, 2004. p. 41-58.

2 Para uma discussão quanto ao nome fundamentalismo e aos adjetivos decorrentes dele, cf. HALE, Frederick. "Fundamentalism" and "fundamentalist" semantically considered their lexical origins, early polysemy, and pejoration. In die Skriflig/In Luce Verbi, v. 47, n. 1, p. 1-8, 2013. 
objetivos a inserção do sagrado no campo da política e das causas nacionais, pois os pluralismos nunca foram bem digeridos pelos adeptos da teologia fundamentalista e de sua consequente visão de mundo.

A despeito do rigor exigido pelo estudo histórico do caso após mais de um século do início do movimento, é preciso levar em conta a flexibilidade e a ampliação do campo semântico do conceito fundamentalismo, que abarca hoje uma multiplicidade e variedade de desdobramentos, nem sempre religiosos. Importa afirmar que o nome fundamentalismo se relaciona com o que foi o movimento nas origens e em sua expansão, mas também pode estar associado, dentre outros fenômenos, ao pentecostalismo, à exploração dos meios de comunicação por pregadores e pastores, à entrada de atores evangélicos na política (nos EUA, mas não somente lá). Quer dizer, grupos fundamentalistas passaram e passam sempre por constantes mutações, reconfiguram-se diante de novas demandas; o fato é que existem diferentes expressões fundamentalistas de acordo com as peculiaridades do grupo religioso em que se manifestam e com que formas respondem às investidas da modernidade.

Chama a atenção a engrenagem principal do funcionamento de todos os grupos fundamentalistas: são uma reação à modernidade e, ao mesmo tempo, apropriam-se dos elementos constituintes dela. Nada a estranhar, pois a própria modernidade é ambígua ao promover a emancipação humana - bem como o aperfeiçoamento dos meios para alcançála - e concomitantemente gerar solidão e abandono. É assim que a oposição moderna à modernidade, representada pelos fundamentalismos (primeiramente, o protestante), ganha força nas rupturas: foi a dinâmica da modernidade que tornou possíveis os fundamentalismos como fenômenos contemporâneos. ${ }^{3}$

\section{Fundamentalismo e neofundamentalismo}

Para aproximar o tema geral ao caso brasileiro, vale trazer à discussão a hipótese de Antonio Gouvêa Mendonça, ${ }^{4}$ não muito difundida e nem sempre debatida, de que a entrada do fundamentalismo protestante no Brasil está associada ao livro Maranatha ou o Senhor vem, de Alfredo Borges Teixeira (teólogo e pastor da Igreja Presbiteriana Independente do Brasil), publicado em 1921, no qual o autor descreve sua conversão ao pré-milenarismo. A constatação de Mendonça parece mais uma intuição do que um dado verificado empiricamente, no que reside sua fragilidade; ainda assim, e a despeito de um reducionismo evidente, pela data em questão, não é uma informação a ser desprezada. As ocorrências no Brasil podem ser tomadas, por comparação, como reflexo de fenômenos

3 BALEEIRO, Cleber A. S. A dinâmica dos fundamentalismos: modernidade e tradição. In: SOUZA, Sandra D. (Org.). Fundamentalismos religiosos contemporâneos. São Paulo: Fonte Editorial, 2013. p. 15-44.

4 MENDONÇA, Antonio G. Vocação ao fundamentalismo: introdução ao espírito do protestantismo de missão no Brasil. In: MENDONÇA, Antonio G.; VELASQUES FILHO, Prócoro. Introdução ao protestantismo no Brasil. São Paulo: Loyola, 1990. p. 133-144. 
religiosos dos EUA, ou seja, o dispensacionalismo pré-milenarista foi ganhando espaço teológico e ético no mundo evangélico até se tornar hegemônico ${ }^{5}$ - para tanto, a contribuição da Scofield Reference Bible foi decisiva a partir de 1909.

Anos depois, na década de 1940, o pastor Carl McIntire reforçou o movimento ao visitar o Brasil para divulgar os princípios do fundamentalismo em sua cruzada contra o Conselho Mundial de Igrejas (CMI); causou alvoroço, dividiu igrejas, abriu e pavimentou caminhos pelos quais o fundamentalismo ingressou em várias denominações nacionais. Como resultado de quase meio século de circulação formal e informal da teologia e do ethos fundamentalista no Brasil, foi a partir de 1950 que o movimento assumiu novas estratégias: criaram-se institutos bíblicos, seminários, acampamentos para jovens e organizações missionárias interdenominacionais - instituições que não tinham interesse direto na formação de novas igrejas, mas na proliferação do fundamentalismo com feição antiecumênica nas igrejas nacionais já consolidadas. ${ }^{6}$

Na segunda metade do século XX, como espécie de complemento ao movimento missionário iniciado no século anterior, projetos de igrejas, denominações e grupos evangélicos independentes (todos estadunidenses) abraçaram como sua intenção a salvação do continente americano. ${ }^{7}$ No Brasil, pregadores dos EUA passaram a influenciar opiniões e comportamentos com seu apelo à conversão religiosa e moral; promoveram-se eventos de massa, com ênfase em orações, curas e exorcismos. Grupos conservadores dos EUA apoiavam economicamente esses pregadores, ${ }^{8}$ que utilizavam estações de rádio, programas televisivos, ruas e praças para a divulgação de sua mensagem.

Não é preciso muita sagacidade para perceber a extensão dos resultados do fundamentalismo no protestantismo brasileiro. Antes de mais nada é uma forma de fé cristã inteiramente voltada para o sobrenatural e para o ahistórico. Não há nenhuma abertura para o social, para a Igreja no mundo. É uma fé passiva em busca de sinais. Não favorece nenhuma reflexão teológica. A fé já está cristalizada na reta doutrina. Não favorece projetos nem gera utopias porque a leitura da Bíblia já está feita. É um dogmatismo escolástico, autoritário e ultraconservador. ${ }^{9}$

5 MARSDEN, George M. Understanding Fundamentalism and Evangelicalism. Grand Rapids: Wm. B. Eerdmans Publishing Co., 1991. p. 39-41.

6 MENDONÇA, 1990, p. 142.

7 Para uma análise - controvertida, é verdade - de certo modelo de cristianismo estadunidense como tábua de salvação para toda a América Latina e Caribe, pela ação das assim chamadas seitas, do pentecostalismo, das agências paraeclesiásticas etc., cf. LIMA, Delcio M. Os demônios descem do Norte. 2. ed. Rio de Janeiro: Francisco Alves, 1987.

8 Vale lembrar que foram empresários do petróleo, os irmãos Stewart, que financiaram a publicação da série The Fundamentals no início do século XX - marco decisivo do movimento fundamentalista originário. MARSDEN, 1991, p. 41.

9 MENDONÇA, 1990, p. 142. 
Para dar sequência à compreensão da passagem do fundamentalismo ao que se convencionou chamar de neofundamentalismo, importa destacar que ele, o neofundamentalismo, ainda causa estranhamento a estudiosos do fenômeno religioso que não conhecem a terminologia ou não a reconhecem como apropriada ou legítima. $\mathrm{O}$ termo é utilizado para designar uma ressignificação do fundamentalismo, nos EUA e também no Brasil, atrelada a um pulsante engajamento político. A fim de continuar uma descrição cronológica não exaustiva, mas necessária, considera-se que o fundamentalismo protestante estadunidense perdeu parte de sua relevância no período que vai da Segunda Guerra Mundial até os anos 1970 (sem que tenha deixado de existir ou circular dentro e fora das denominações protestantes). ${ }^{10}$ A passagem desse período menos ativo do fundamentalismo clássico para o que se convencionou classificar de neofundamentalismo foi marcada por crises econômicas e sociais. ${ }^{11}$

Depois de anos seguidos de crises econômicas e políticas em contexto de Guerra Fria, os protestantes estadunidenses ligados ao movimento fundamentalista a partir do final dos anos 1960 tiveram de conviver também com a crise de valores ocidentais tradicionais, principalmente em virtude de projetos sociais que ampliavam direitos civis e de minorias; a contracultura era outro movimento que colocava em xeque a sociedade tradicionalmente constituída, pois impregnava vários setores sociais e atraía os mais jovens. "Pode se dizer, como foi assinalado no fundamentalismo clássico, que os movimentos fundamentalistas são sempre gerados e nutridos por sociedades em crises" ${ }^{12}$ Em linhas gerais, portanto, o neofundamentalismo pode ser entendido como uma reformulação do movimento fundamentalista, com o intuito de recuperar a moralidade protestante na sociedade - primeiramente nos EUA, mas não somente lá, posto que artigo de exportação. Os neofundamentalistas, desde a primeira hora, acreditaram que o projeto de reconquista da sociedade deve passar pela inserção e ocupação de espaços na esfera pública.

Ligados aos meios de comunicação, ${ }^{13}$ os neofundamentalistas entenderam ter em suas palavras e mãos a solução para as crises; acusavam o Estado de haver tolerado "demônios" responsáveis pela crise social e declínio da fé em assuntos como legalização do aborto, direitos aos homossexuais, influências do comunismo na economia e sociedade. Todos os temas, como é de se observar, estavam em não conformidade com a verdade de uma interpretação particular das Escrituras. A fraqueza do Estado em defender e garantir

10 Parte da perda de importância social do fundamentalismo pode ser creditada simbolicamente ao famoso julgamento de Scopes acerca do ensino da teoria da evolução no Estado do Tennessee, EUA, em 1925. MARSDEN, 1991, p. 60.

11 ORO, Ivo P. O outro é o demônio: uma análise sociológica do fundamentalismo. São Paulo: Paulus, 1996. p. 75-105.

12 ORO, 1996, p. 75.

13 Para uma leitura das relações dos fundamentalistas e neofundamentalistas dos EUA com a América Latina (e Brasil, é claro), segundo o uso dos meios de comunicação pelos evangélicos, cf. ASSMANN, Hugo. A igreja eletrônica e seu impacto na América Latina: convite a um estudo. Petrópolis: Vozes, 1986. 
a ordem social nos moldes da moral tradicional levou o neofundamentalismo à concepção de que a sociedade deve ter no religioso o referencial válido e eficaz para orientar todos os indivíduos e não somente os aderentes: “[...] na escalada dos anos 75-80, o fundamentalismo faz a passagem do protesto sociocultural para o engajamento político".${ }^{14}$

Um exemplo de operacionalização do neofundamentalismo nos EUA ocorreu em 1980 com o apoio da Moral Majority15 à candidatura vitoriosa de Ronald Reagan. Na campanha eleitoral destacaram-se temas como a proibição do aborto e o apoio a projetos de ensino religioso nas escolas. Marcados por interesses políticos, os tele-evangelistas ocuparam todos os espaços possíveis da esfera pública naquelas eleições: "lideranças de tais movimentos [de intervenção e pressão política], como Jerry Falwell e Pat Robertson, defendiam um projeto de recristianização da sociedade" ${ }^{16}$

\section{Fundamentalismo e pentecostalismo}

Para ampliar a compreensão da associação entre fundamentalismo, neofundamentalismo e pentecostalismo, registra-se de início uma proposição de Saulo de Tarso Cerqueira Baptista:

O fundamentalismo e o pentecostalismo são movimentos contemporâneos e simultâneos. Ambos nasceram na passagem do século XIX para o século XX, nos Estados Unidos da América. A partir daí cresceram, foram disseminados pelo mundo, consolidaram-se e continuam a se alimentar reciprocamente. Defenderemos a seguinte tese: o pentecostalismo, que hoje se desdobra em centenas de igrejas institucionalizadas, é um tipo de fundamentalismo. ${ }^{17}$

Mesmo levando em conta a plausibilidade da tese de Baptista, há de se registrar que, orgulhosos de sua racionalidade, muitos fundamentalistas ao longo de todo o século $\mathrm{XX}$ questionaram os pentecostais por causa do aspecto emocional de sua religiosidade e também por uma suposta falta de fidelidade doutrinária. Como efeito não intencional num primeiro momento, adotar o fundamentalismo foi uma saída para o pentecostalismo agregar doutrina a sua forma de ser religião:

14 ORO, 1996, p. 97.

15 Marsden compara a importância do fundador da Moral Majority, Jerry Falwell, para o fundamentalismo à de Billy Graham para o evangelicalismo: "Jerry Falwell foi de fato um reformador do fundamentalismo, cuja regra, de certa forma, acompanhou à de Graham e seu grupo neo-evangelical dos anos 1950. ‘Neofundamentalista' é um termo apropriado para o movimento de Falwell”. MARSDEN, 1991, p. 76; tradução nossa.

16 ROCHA, Daniel. Venha a nós o vosso reino: rupturas e permanências nas relações entre escatologia e política no pentecostalismo brasileiro. Belo Horizonte: PUC Minas Gerais, 2009. p. 64.

17 BAPTISTA, Saulo T. C. Fora do mundo - dentro da política: identidade e "missão parlamentar" da Assembleia de Deus em Belém. Belém: Universidade Federal do Pará, 2002. p. 12. 
[...] o pentecostalismo aproxima-se bastante do fundamentalismo, ao aceitar a inerrância do texto bíblico. A Bíblia é tida como a única regra de fé e prática. As prescrições presentes na Bíblia, sobre qualquer assunto, não devem ser questionadas, mas obedecidas. ${ }^{18}$

Em contrapartida, os pentecostais continuam a aceitar tacitamente que fundamentalistas (no protestantismo histórico, por exemplo) não possuem a unção do Espírito, o que os prejudica em sua compreensão da Bíblia. ${ }^{19}$

Para associar neofundamentalismo e pentecostalismo, registra-se a seguinte opinião de Daniel Rocha:

A retórica neofundamentalista de politização do religioso pode ser considerada umas das principais motivadoras da inserção dos pentecostais na política brasileira. Muito do discurso legitimador de tal inserção [...] parece ter saído diretamente da boca de um representante da Moral Majority ou da Coalização Cristã [que são movimentos estadunidenses]. ${ }^{20}$

O neofundamentalismo pode ser identificado, portanto, pelo ingresso de igrejas principalmente pentecostais no campo político, pois as instituições de matriz pentecostal assumiram esta fórmula de superação de crises: a moral cristã como salvação da pátria.

No Brasil, o neofundamentalismo também se observa, dentre outros espaços, no âmbito da atuação política. O discurso de parlamentares evangélicos e católicos em defesa da família traz em seu bojo críticas à luta pelos direitos reprodutivos das mulheres, pelos direitos da população LGBT e pelos direitos das profissionais do sexo. Apresentando-se como críticos da decadência moral da sociedade, os neofundamentalistas interferem em políticas públicas direcionadas para as mulheres, como a descriminalização do aborto, o direito ao aborto nos casos previstos por lei, a educação sexual nas escolas públicas, que é um importante mecanismo para evitar a gravidez na adolescência etc. ${ }^{21}$

Para os neofundamentalistas, os direitos humanos devem se submeter às leis de Deus: premissa que sustenta, por exemplo, projetos e votos da "bancada evangélica" ou "bancada da Bíblia" no Brasil contemporâneo. Nota-se que há uma ocupação do espaço

18 SIEPIERSKI, Paulo D. Contribuições para uma tipologia do pentecostalismo brasileiro. In: GUERRIERO, Silas (Org.). O estudo das religiões: desafios contemporâneos. São Paulo: Paulinas, 2003. p. 74.

19 Por comparação, o fundamentalismo é racional e o pentecostalismo é emocional, posto que caracterizado pelo batismo com o Espírito Santo e pela contemporaneidade dos dons (com ênfase na glossolalia). Por isso é que pentecostais, a fim ocupar certo vazio doutrinal, adotam um conjunto de dogmas fundamentalistas. BAPTISTA, Saulo T. C. Fundamentalismo evangélico brasileiro: construção de um tipo ideal weberiano. Anais do Simpósio da $A B H R$ - Religião, carisma e poder: as formas da vida religiosa no Brasil, 2012. p. 1-14.

20 ROCHA, 2009, p. 71.

21 SOUZA, Sandra D. Implicações do fundamentalismo islâmico para a emancipação das mulheres. In: SOUZA, Sandra D. (Org.). Fundamentalismos religiosos contemporâneos. São Paulo: Fonte Editorial, 2013. p. 215. 
político por igrejas evangélicas, um aumento do número de cristãos que consideram o exercício político uma função compatível com as normas morais e espirituais. Mais do que compatível com as atividades das igrejas, para o neofundamentalismo, a atividade política passa a ser uma exigência delas. O discurso moral dos políticos evangélicos é justificado por eles mesmos como democrático - porém, trata-se de uma democracia que não leva em conta os direitos e as liberdades individuais ou de algumas minorias, nem dá atenção à laicidade do Estado.

Em diálogo com o texto "Os políticos de Cristo - uma análise do comportamento político de protestantes históricos e pentecostais no Brasil" de Leonildo Silveira Campos, ${ }^{22}$ Emerson Roberto da Costa menciona que o autor divide os atores religiosos (evangélicos) implicados na política em dois modelos típico-ideais (concebidos segundo metodologia weberiana):

[...] o "político evangélico", o qual designa agentes de origem protestante, surgidos no tempo da República Velha; e o segundo tipo, os chamados "políticos de Cristo", o qual desenvolveu-se a partir da promulgação da Constituição de 1988, que se "caracterizam pelo fato de serem escolhidos, eleitos e, eventualmente, afastados da política pela Igreja que comanda a sua ação política". 23

Ainda em diálogo com Campos - acrescido da participação de Baptista ${ }^{24}$-, Costa acrescenta que para um "político de Cristo" não importa tanto atuar num partido ideológico, quer seja de oposição ou de situação, mas, antes, estar num partido que lhe traga chances reais de ser eleito. Nessa lógica, candidatos de igrejas diferentes duelam em pleitos eleitorais como os únicos competentes para restaurar a moral e livrar a sociedade dos males que a acometem, bem como para garantir paz e prosperidade aos fiéis. Assim, muitos parlamentares evangélicos no Brasil contemporâneo utilizam bandeiras em comum e ao mesmo tempo rivalizam entre si, independentemente de partido político, para operar num viés que promova a defesa da família, moral e religião cristãs; depois, no pleno exercício do mandato, acabam por se encontrar na bancada evangélica, que é de natureza e funcionamento suprapartidários.

No Brasil, como se sabe, os protestantes ou evangélicos tiveram seus direitos religiosos, políticos e sociais garantidos in totum com a Proclamação da República e a

22 CAMPOS, Leonildo S. Os políticos de Cristo - uma análise do comportamento político de protestantes históricos e pentecostais no Brasil. In: BURITY, Joanildo A.; MACHADO, Maria D. C. (Orgs.). Os votos de Deus: evangélicos, política e eleições no Brasil. Recife: Fund. Joaquim Nabuco/Massangana, 2006. p. 2990.

23 COSTA, Emerson R. O fundamentalismo evangélico e a política brasileira. In: SOUZA, Sandra D. (Org.). Fundamentalismos Religiosos Contemporâneos. São Paulo: Fonte Editorial, 2013. p. 79-80.

24 BAPTISTA, Saulo T. C. Cultura política brasileira, práticas pentecostais e neopentecostais: a presença da Assembleia de Deus e da Igreja Universal do Reino de Deus no Congresso Nacional (1999-2006). São Bernardo do Campo: Universidade Metodista de São Paulo, 2007. p. 138-139. 
Constituição de 1891; contudo, no período da República Velha, estiveram ausentes ou distantes da atuação na esfera público-política, com raras exceções. ${ }^{25}$ Participação mais efetiva de protestantes na política se deu a partir nos anos de 1930, em virtude do receio por parte de setores evangélicos brasileiros de um possível ou conspiratório restabelecimento da união entre Igreja (católico-romana) e Estado; foi, então, que alguns protestantes julgaram ser pertinente o ingresso na ação político-partidária a fim de lutar pela garantia de seus direitos.

No período da ditadura militar (1964-1985), algumas igrejas protestantes apoiaram o regime de exceção; em menor número, outras preferiram fazer oposição a ele. A partir de 1966, houve um equilíbrio mais evidente entre as tendências favoráveis e contrárias ao golpe. ${ }^{26}$ Para Robinson Cavalcanti, setores protestantes que tinham nenhuma ou pouca participação política aproximaram-se do regime ditatorial, pois acreditavam que apoiar o governo seria apoiar também o progresso do cristianismo; ser contra ele, portanto, seria o mesmo que contribuir para o fim do cristianismo numa nítida aliança com o ateísmo sob a égide do apoio ao comunismo.

Participar da política era válido, desde que a favor do governo. Rapidamente Romanos 13, com sua original interpretação, foi promovido a "texto áureo" dos evangélicos ARENA-PDS. Votar na oposição passou a ser pecado. Uma visão maniqueísta passou a ter a oposição como constituída de maus: os comunistas. Na maioria das igrejas, quem não pensasse assim seria perseguido ou posto "no gelo". ${ }^{27}$

No locus simbólico e formal de oposição ao pensamento e ação de apoio à ditadura, ainda segundo Cavalcanti, ${ }^{28}$ as igrejas evangélicas no Brasil se dividiram: de um lado, as de tendência liberal em teologia e socialista em política, ligadas a organismos ecumênicos; de outro, aquelas de tendência conservadora em teologia (evangelicalismo, missão integral etc.) e liberal em política.

A participação evangélica na política brasileira ficou mais evidente com o fim da ditadura militar e o advento da redemocratização. Com a abertura democrática e o estabelecimento da Assembleia Nacional Constituinte, setores evangélicos conservadores acusaram (de novo) uma possível união entre Igreja Católica e Estado, assim como a ampliação de direitos às minorias. A fim de lutar contra suas suspeitas, infundadas ou não, evangélicos participaram das eleições com candidatos à Constituinte:

25 FRESTON, Paul. Protestantes e politica no Brasil: da constituinte ao impeachment. Campinas: UNICAMP, 1993. p. 149-179.

26 PEDDE, Valdir; SANTOS, Everton R. A inserção dos pentecostais na política: uma ameaça à democracia? História Unisinos, v. 13, n. 3, p. 284-296, set./dez. 2009.

27 CAVALCANTI, Robinson. Cristianismo e política: teoria bíblica e prática histórica. Viçosa: Ultimato, 2002. p. 229.

28 CAVALCANTI, 2002, p. 229-231. 
No caso brasileiro, mais especificamente no período da redemocratização, o pleito de 1986, que elegeu deputados constituintes, trouxe consigo grandes surpresas. Nessas eleições, as igrejas pentecostais elegeram 32 evangélicos; deste total, 14 pertenciam aos quadros da Assembleia de Deus, dois, à Igreja Quadrangular e um, à Igreja Universal. De modo geral, esses evangélicos votaram a favor de propostas conservadoras, além de se envolverem em trocas de favores e receberem concessões de rádio e televisão pelo apoio às propostas do governo. ${ }^{29}$

Compreende-se, portanto, que esses novos movimentos de igrejas pentecostais eclodiram com uma visão neofundamentalista a partir dos anos de 1980 no Brasil e se consolidaram a partir de 1986 com sua participação na Constituinte e, pouco depois, com as eleições de 1989.30

\title{
Fundamentalismo e neopentecostalismo (pós-pentecostalismo)
}

A radicalização do processo de inserção de evangélicos na arena política se deu mesmo pela ação das igrejas neopentecostais, cujo substrato teológico (reconstrucionismo, teologia do domínio, batalha espiritual etc.) advém de interpretações muito particulares de textos bíblicos selecionados arbitrariamente - que representa uma prática diferente daquela do fundamentalismo dos pentecostais, mais clássico e ligado ao dos protestantes históricos.

\begin{abstract}
Outra questão que deve ser colocada em pauta para a revisão é o conceito de fundamentalismo aplicado ao neopentecostalismo. Isso tem sido feito talvez por falta de observação e equívoco quanto ao sentido de fundamentalismo. Os neopentecostais não usam o texto bíblico primordialmente como repositório da verdade, mas como motivação para a prédica e a prática. A Bíblia, para eles, parece ser um repositório de "contos exemplares". Não se nota entre eles, nessa prática, o dogmatismo típico do fundamentalismo e nem mesmo tentativa de imposição de verdades literais. Fazem, sem dúvida, leituras literais da Bíblia, mas com sentido ilustrativo. Reconhecemos a necessidade, entretanto, de observar melhor a prática bíblica neopentecostal, mas pode ser equivocado incluí-los simplesmente entre os fundamentalistas. ${ }^{31}$
\end{abstract}

Ou seja, os fiéis neopentecostais estão aí muito mais para obedecer à palavra de seu líder - apóstolo, bispo, missionário, pastor etc. - do que propriamente para se firmar no literalismo do texto sagrado.

29 PEDDE; SANTOS, p. 290, 2009.

30 FRESTON, 1993, p. 222-266.

31 MENDONÇA, Antonio G. Protestantismo brasileiro, uma breve interpretação histórica. In: SOUZA, Beatriz M.; MARTINO, Luís M. S. (Orgs.). Sociologia da religião e mudança social: católicos, protestantes e novos movimentos religiosos no Brasil. São Paulo: Paulus, 2004. p. 75. 
Segundo Paulo Donizéti Siepierski, as igrejas neopentecostais, chamadas por ele de pós-pentecostais, deixaram de lado a teologia pentecostal inicial e suas consequências éticas (sectarismo, distanciamento da mídia, apoliticismo, negação de bens materiais etc.) para aderir à política como um novo elemento de ação. Siepierski, portanto, propõe um novo modelo de classificação para além daquele das três ondas ${ }^{32}$ no pentecostalismo brasileiro:

Se Mariano foi feliz ao classificar a segunda onda de pentecostalismo neoclássico, o mesmo não acontece em relação à terceira onda, pois ele aceita de forma não crítica o termo neopentecostal. Mesmo reconhecendo que o termo tem sido empregado com imprecisão, ele aceita-o simplesmente por ser o "que mais vem ganhando terreno nos últimos anos entre os pesquisadores brasileiros para classificar as novas Igrejas pentecostais". A inadequação do termo fica evidente quando o próprio Mariano reconhece que, "enquanto as duas primeiras ondas não apresentam diferenças teológicas significativas entre si, verifica-se justamente o oposto quando se compara o neopentecostalismo às vertentes pentecostais que o precederam". Ora, se o neoclássico é o neo porque não difere significativamente do clássico, por que neopentecostalismo se ele difere sobremaneira do pentecostalismo que o precedeu? Ademais, tradicionalmente, o prefixo neo tem sido relacionado com continuidade e não com ruptura. ${ }^{33}$

Como consequência de seus pressupostos, Siepierski apresenta a tese de que o pós-pentecostalismo está distante do pentecostalismo por não guardar alguns de seus elementos, como biblicismo, união da fé com a ética etc.; e mais distante ainda do protestantismo histórico, por romper com os princípios basilares da Reforma. “O póspentecostalismo é genealogicamente protestante, mas não o é teologicamente". ${ }^{34}$ Noutros termos:

[...] pode-se definir o pós-pentecostalismo, na perspectiva de Siepierski, como: um afastamento (quase uma ruptura) do pentecostalismo clássico cuja mensagem enfatiza a teologia da prosperidade e a batalha espiritual e que foi "teologicamente viabilizado" por uma mudança na ênfase escatológica, abandonando-se o pré-milenarismo, abraçando uma escatologia que valoriza o presente e a vida intramundana. Além disso, tal movimento teria uma face política marcada pelo engajamento eleitoral para a eleição de parlamentares ligados às igrejas com o objetivo último de estabelecer uma nova cristandade. ${ }^{35}$

32 Cf. MARIANO, Ricardo. Neopentecostais: sociologia do novo pentecostalismo no Brasil. 2. ed. São Paulo: Loyola, 2005.

33 SIEPIERSKI, 2003, p. 74.

34 SIEPIERSKI, Paulo D. Pós-pentecostalismo e política no Brasil. Estudos Teológicos, São Leopoldo, v. 37, p. 52, 1997.

35 PASSOS, Mauro; ROCHA, Daniel. Em tempos de pós-pentecostalismo: repensando a contribuição de Paulo Siepierski para o estudo do pentecostalismo brasileiro. Revista Angelus Novus, n. 3, p. 275, 2012. 
A Igreja Universal do Reino de Deus (IURD), fundada em 1977 e liderada até hoje por Edir Macedo, pode ser tomada como o primeiro modelo desse novo pentecostalismo (neo ou pós), ${ }^{36}$ pois chamam a atenção os espaços sociais e políticos conquistados pela IURD nos últimos anos, inclusive por ação partidária e disputas eleitorais, cuja última grande realização está relacionada à eleição de Marcelo Crivella (PRB - Partido Republicano Brasileiro) para a prefeitura do Rio de Janeiro em 2016. Numa análise sociológica e ao mesmo tempo teológica concernente ao comportamento dos fiéis, o modelo das igrejas e denominações pós-pentecostais entende que o reino de Deus é preparado por sua ação, o que aproxima sua ação da visão escatológica pós-milenarista e permite entendê-la à luz da teologia do reconstrucionismo e da batalha espiritual.

Assim, o pós-pentecostalismo é um afastamento do pentecostalismo tendo como cerne a teologia da prosperidade e o conceito de guerra espiritual. Tal afastamento só foi possível mediante a gradual substituição do prémilenarismo pelo pós-milenarismo. Os traços característicos incluem uma mistura deliberada de religiosidade popular, a utilização autoconsciente de estilos e convenções anteriores, a construção de estruturas comerciais, o abandono dos sinais externos de santidade e, frequentemente, a incorporação de imagens relacionadas com o consumismo e a comunicação de massa da sociedade pós-industrial do final do século XX. Seu objetivo declarado é estabelecer uma nova cristandade por meio da atividade política. ${ }^{37}$

Em contrapartida e para relativizar a discussão, importa mencionar que as igrejas pós-pentecostais guardam em seu discurso escatológico aspectos do imaginário das igrejas pentecostais clássicas, ou seja, segundo a concepção pré-milenarista, pelo menos no que tange à parousia e ao segundo advento de Cristo - o que representa uma estrutura a condicionar mentalidades e comportamentos individuais e coletivos.

[...] A partir da entrada dos pentecostais na política eleitoral, a utilização dos conceitos de pré-milenarismo e pós-milenarismo se tornam problemáticos e tendem [sic] a obscurecer mais do que desvelar o fenômeno pentecostal. As concepções escatológicas no pentecostalismo brasileiro são marcadas por continuidades e rupturas: ao mesmo tempo em que confessam o pré-milenarismo e, ainda, outras expectativas, influenciadas pelas crenças propagadas pelo pós-pentecostalismo, indicariam para uma escatologia presente da Batalha Espiritual. Na perspectiva da longa duração, pode-se perceber a presença de elementos heterogêneos na formação de um amálgama de concepções escatológicas. ${ }^{38}$

36 SIEPIERSKI, 1997.

37 SIEPIERSKI, 2003, p. 79.

38 ROCHA, 2009, p. 14; para uma defesa mais radical de que pós-pentecostalismo é também pós-milenarismo, cf. SIEPIERSKI, 2003. 
O pós-pentecostalismo deve ser considerado uma nova estrutura em relação ao pentecostalismo clássico do início do século XX. A estrutura antiga rompeu-se e deu origem a uma nova estrutura flexível no mundo moderno. Por essa flexibilização, deu-se a entrada da teologia da prosperidade, os engajamentos políticos e a proliferação de conteúdos religiosos em diferentes meios de comunicação.

\section{Considerações Finais}

Para concluir é preciso reconhecer que a principal contribuição deste artigo à compreensão do campo protestante ou evangélico no Brasil reside na explicitação de que o termo fundamentalismo, depois de haver experimentado uma ampliação considerável de seu campo semântico durante todo o século XX, está hoje associado a vários fenômenos, religiosos ou não, com a devida legitimidade que o uso social confere à palavra em cada caso. Do nome à coisa, as possibilidades são tantas que é difícil ao investigador não passar pela mesma experiência de Michel Foucault - "do riso que [...] perturba todas as familiaridades do pensamento" 39 - em face do sistema de divisão e classificação dos animais proposto por uma enciclopédia chinesa intitulada Empório Celestial de Conhecimentos Benévolos, de acordo com o registro textual de Jorge Luis Borges.

Em suas remotas páginas consta que os animais se dividem em (a) pertencentes ao Imperador, (b) embalsamados, (c) amestrados, (d) leitões, (e) sereias, (f) fabulosos, (g) cães soltos, (h) incluídos nesta classificação, (i) que se agitam como loucos, (j) inumeráveis, (k) desenhados com um finíssimo pincel de pelo de camelo, (l) etcétera, (m) que acabam de quebrar o vaso, (n) que de longe parecem moscas. ${ }^{40}$

A conclusão de Borges: não há classificação que não seja arbitrária. "A impossibilidade de penetrar o esquema divino do universo não pode, contudo, dissuadirnos de planejar esquemas humanos, mesmo sabendo que eles são provisórios". ${ }^{41}$ Daí o riso (nervoso) de Foucault, acompanhado de mal-estar, pois todo ordenamento que consola é também desordem.

Qual a divisão e classificação possíveis dos evangélicos no Brasil? Em 1989, no artigo "Um critério de classificação religiosa", Mendonça reconhecia a dificuldade de toda e qualquer taxonomia: "[...] quando a gente faz uma proposta de classificação é preciso dar o critério dessa classificação. E é claro que a escolha de um significa a exclusão de outros critérios tão válidos e possíveis quanto aquele". ${ }^{42}$ Do geral para o particular, ou seja, do universo evangélico todo para a presença do fundamentalismo nele - e dada a

39 FOUCAULT, Michel. As palavras e as coisas: uma arqueologia das ciências humanas. 7. ed. São Paulo: Martins Fontes, 1995. p. 5.

40 BORGES, Jorge L. Outras inquisições. In: BORGES, Jorge L. Obras completas, v. II, 1952-1972. São Paulo: Globo, 1999. p. 94.

41 BORGES, 1999, p. 95.

42 MENDONÇA, Antonio G. Um critério de classificação religiosa. Cadernos do ISER, n. 21, p. 73, 1989. 
complexidade do caso -, nas seções anteriores foi perseguida a relação entre fundamentalismo e neofundamentalismo, pentecostalismo e neopentecostalismo (ou póspentecostalismo), sempre no diálogo entre o que ocorreu originalmente nos EUA e os desdobramentos do caso nas terras e gentes brasileiras no desenrolar do século XX. Parece unânime a afirmação de que é mais fácil observar - para descrever - o que fazem os fundamentalistas do que tentar definir o que é o fundamentalismo.

O que fazem, então, os fundamentalistas? Eles leem literalmente a Bíblia e aplicam os ensinamentos morais extraídos dela em sua conduta, como é o caso da maioria dos protestantes históricos e pentecostais clássicos; eles podem também ler a Bíblia indiretamente, quer dizer, por meio do discurso de líderes - apóstolos, bispos, pastores, missionários etc. -, ainda assim, a Bíblia continua a ser responsável por determinação de conduta, como no caso das igrejas neo ou pós-pentecostais. No primeiro modelo, há a renúncia do mundo exigida do fiel; no segundo, solicita-se dele o engajamento na sociedade e a ação política é, assim, a via privilegiada. A construção do reino dos céus (de Deus) na Terra (entre as pessoas) parece ser, pelo lado teórico-teológico, a motivação da mentalidade e ação dos pós-pentecostais; por outro lado, falar em reconstrução da cristandade, que já seria um problema em si, mostra-se exagerado, pois o que querem as igrejas pós-pentecostais está muito mais ligado a seus interesses e aos de seus líderes do que à instauração de um estado de bem-estar para todos.

Enfim, o caso é mesmo complexo, o que impossibilita qualquer tentativa de definição, mas há elementos comuns que atravessam as muitas faces e fases do fundamentalismo no Brasil. Do pré-milenarismo de Alfredo Borges Teixeira ao pósmilenarismo pero no mucho dos pós-pentecostais (representados, por exemplo, pela IURD), o outro deve ser conquistado, por conversão espontânea ou forçada, à verdade fundamentalista. No início do século XX, o meio privilegiado para isso era a publicação de livros, as pregações, as cruzadas evangelísticas, os institutos bíblicos etc. - lugares para discursos que, com o passar do tempo e o advento de novas tecnologias, migraram para os meios de comunicação à disposição da sociedade. Hoje, o fanatismo fundamentalista se vale também, e preferencialmente, da ação de políticos ligados a igrejas e líderes de igrejas. É mesmo uma tarefa complicada classificar tudo isso ou dar nome a todas as coisas; todo esquema humano é e será transitório. Difícil também não rir de nervoso diante de tanta perturbação.

\section{Referências}

ASSMANN, Hugo. A igreja eletrônica e seu impacto na América Latina: convite a um estudo. Petrópolis: Vozes, 1986. 
BALEEIRO, Cleber A. S. A dinâmica dos fundamentalismos: modernidade e tradição. In: SOUZA, Sandra D. (Org.). Fundamentalismos religiosos contemporâneos. São Paulo: Fonte Editorial, 2013.

BAPTISTA, Saulo T. C. Cultura política brasileira, práticas pentecostais e neopentecostais: a presença da Assembleia de Deus e da Igreja Universal do Reino de Deus no Congresso Nacional (1999-2006). São Bernardo do Campo: Universidade Metodista de São Paulo, 2007.

. Fora do mundo - dentro da política: identidade e "missão parlamentar" da Assembleia de Deus em Belém. Belém: Universidade Federal do Pará, 2002.

. Fundamentalismo evangélico brasileiro: construção de um tipo ideal weberiano. Anais do Simpósio da ABHR - Religião, carisma e poder: as formas da vida religiosa no Brasil, 2012.

BORGES, Jorge L. Outras inquisições. In: BORGES, Jorge L. Obras completas, v. II, 19521972. São Paulo: Globo, 1999.

CAMPOS, Leonildo S. Os políticos de Cristo - uma análise do comportamento político de protestantes históricos e pentecostais no Brasil. In: BURITY, Joanildo A.; MACHADO, Maria D. C. (Orgs.). Os votos de Deus: evangélicos, política e eleições no Brasil. Recife: Fund. Joaquim Nabuco/Massangana, 2006.

CAVALCANTI, Robinson. Cristianismo e política: teoria bíblica e prática histórica. Viçosa: Ultimato, 2002.

COSTA, Emerson R. O fundamentalismo evangélico e a política brasileira. In: SOUZA, Sandra D. (Org.). Fundamentalismos Religiosos Contemporâneos. São Paulo: Fonte Editorial, 2013.

FOUCAULT, Michel. As palavras e as coisas: uma arqueologia das ciências humanas. 7. ed. São Paulo: Martins Fontes, 1995.

FRESTON, Paul. Protestantes e politica no Brasil: da constituinte ao impeachment. Campinas: UNICAMP, 1993.

HALE, Frederick. "Fundamentalism" and "fundamentalist" semantically considered their lexical origins, early polysemy, and pejoration. In die Skriflig/In Luce Verbi, v. 47, n. 1, p. 1-8, 2013.

LIMA, Delcio M. Os demônios descem do Norte. 2. ed. Rio de Janeiro: Francisco Alves, 1987.

MARIANO, Ricardo. Neopentecostais: sociologia do novo pentecostalismo no Brasil. 2. ed. São Paulo: Loyola, 2005.

MARSDEN, George M. Understanding Fundamentalism and Evangelicalism. Grand Rapids: Wm. B. Eerdmans Publishing Co., 1991. 
MENDONÇA, Antonio G. Protestantismo brasileiro, uma breve interpretação histórica. In: SOUZA, Beatriz M.; MARTINO, Luís M. S. (Orgs.). Sociologia da religião e mudança social: católicos, protestantes e novos movimentos religiosos no Brasil. São Paulo: Paulus, 2004. . Um critério de classificação religiosa. Cadernos do ISER, n. 21, 1989.

. Vocação ao fundamentalismo: introdução ao espírito do protestantismo de missão no Brasil. In: MENDONÇA, Antonio G.; VELASQUES FILHO, Prócoro. Introdução ao protestantismo no Brasil. São Paulo: Loyola, 1990.

ORO, Ivo P. O outro é o demônio: uma análise sociológica do fundamentalismo. São Paulo: Paulus, 1996.

PASSOS, Mauro; ROCHA, Daniel. Em tempos de pós-pentecostalismo: repensando a contribuição de Paulo Siepierski para o estudo do pentecostalismo brasileiro. Revista Angelus Novus, n. 3, 2012.

PEDDE, Valdir; SANTOS, Everton R. A inserção dos pentecostais na política: uma ameaça à democracia? História Unisinos, v. 13, n. 3, p. 284-296, set./ dez. 2009.

ROCHA, Daniel. Venha a nós o vosso reino: rupturas e permanências nas relações entre escatologia e política no pentecostalismo brasileiro. Belo Horizonte: PUC Minas Gerais, 2009.

SIEPIERSKI, Paulo D. Contribuições para uma tipologia do pentecostalismo brasileiro. In: GUERRIERO, Silas (Org.). O estudo das religiões: desafios contemporâneos. São Paulo: Paulinas, 2003.

1997.

. Pós-pentecostalismo e política no Brasil. Estudos Teológicos, São Leopoldo, v. 37,

SOUZA, Sandra D. Implicações do fundamentalismo islâmico para a emancipação das mulheres. In: SOUZA, Sandra D. (Org.). Fundamentalismos religiosos contemporâneos. São Paulo: Fonte Editorial, 2013.

WITHERUP, Ronald D. Fundamentalismo bíblico: o que todo católico deveria saber. São Paulo: Ave-Maria, 2004. 